Canadian

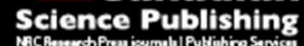

Canadian Journal of Chemistry Revue canadienne de chimie

\title{
Successive Outermost-to-Core Shell Directionality of the Protonation of Poly(Propyl Ether Imine) Dendritic Gene Delivery Vectors
}

\begin{tabular}{|r|l|}
\hline Journal: & Canadian Journal of Chemistry \\
\hline Manuscript ID & cjc-2017-0153.R1 \\
\hline Danuscript Type: & Article \\
\hline Complete List of Authors: & $\begin{array}{l}\text { Lakshminarayanan, Abirami ; Indian Institute of Science, Department of } \\
\text { Organic Chemistry } \\
\text { Jayaraman, Narayanaswamy; Indian Institute of Science, Department of } \\
\text { Organic Chemistry }\end{array}$ \\
\hline $\begin{array}{r}\text { Is the invited manuscript for } \\
\text { consideration in a Special } \\
\text { Issue?: }\end{array}$ & Dendimers \\
\hline Keyword: & Buffering capacity, Dendrimers, Gene delivery, Ising model, Polycations \\
\hline & \multicolumn{2}{|c|}{} \\
\hline
\end{tabular}

SCHOLARONE ${ }^{m}$

Manuscripts 
1 Successive Outermost-to-Core Shell Directionality of the Protonation of 2 Poly(Propyl Ether Imine) Dendritic Gene Delivery Vectors

3 Abirami Lakshminarayanan and Narayanaswamy Jayaraman*

4

5 Dr. Abirami Lakshminarayanan, Prof. Narayanaswamy Jayaraman

6 Department of Organic Chemistry, Indian Institute of Science, Bangalore, 560012, India

7 E-mail: jayaraman@orgchem.iisc.ernet.in 
1 Abstract. The protonation behaviour of polycationic compounds have direct relevance to their

2 ability to condense and deliver nucleic acids. This report pertains to a study of the protonation

3 behaviour of polycationic poly(propyl ether imine) (PETIM) dendritic gene delivery vectors, that

4 are constituted with tertiary amine core moiety and branch sites, n-propyl ether linkages and

5 primary amine peripheries. The ability of this series of dendrimers to condense nucleic acids and

6 mediate endosomal escape was studied by unravelling the protonation behaviour of the

7 dendrimers aided by $\mathrm{pH}$-metric titrations, ${ }^{1} \mathrm{H}$ and ${ }^{15} \mathrm{~N}$ NMR spectroscopies. The results

8 demonstrate protonation of the primary and tertiary amines of outermost-to-core shells occurring

9 in a successive step-wise fashion, in contrast to other polycationic vectors. Theoretical

10 calculations based on the Ising model rationalize further the finer details of protonation at each

11 shell. The protonation pattern correlates with the endosomal buffering and nucleic acid

12 condensation properties of this PETIM based dendritic gene delivery vectors. The study

13 establishes that the protonation behaviour is a critical and essential parameter in order to assess

14 the gene condensation and delivery vector properties of a polycationic compound.

15 Keywords: Buffering capacity; Dendrimers; Gene delivery; Ising model; Polycations 


\section{Introduction}

2 Synthetic vectors are important tools in order to achieve successful gene delivery, by

3 overcoming various physiological barriers. ${ }^{1}$ Nucleic acid condensation by a vector and

4 subsequent endosomal escape of the complex are tunable through site-specific modifications of

5 the synthetic vector. Few examples are the cyclodextrins, ${ }^{2}$ triazines, ${ }^{3}$ histidine, imidazole, ${ }^{4}$ poly-

6 lysine $^{5}$ and cations ${ }^{6}$ that facilitate increased nucleic acid condensation and endosomal escape.

7 Determining the effects of chemical modifications of a synthetic vector is optimal and provides

8 invaluable information about the gene transfection properties of a synthetic vector. Identifying

9 the protonation behavior of a cationic vector is important in this context. Whereas theoretical

10 studies based on molecular dynamic simulations have highlighted the importance of protonation

11 behavior, ${ }^{7,8}$ only few reports concerning the development of synthetic polycationic vectors for

12 gene delivery consider this important aspect. Earlier studies established the protonation of

13 polycationic poly(amidoamine) (PAMAM) and poly(propylene imine) (PPI) dendrimers, ${ }^{9,10}$ as

14 well as, linear and branched polyethylene imine (PEI), ${ }^{9}$ chitosan, ${ }^{11}$ poly(acrylic acid) (PAA) and

15 poly(methylacrylic acid) (PMAA) polymers. ${ }^{12}$ The studies demonstrate that protonation of

16 cationic sites influence polymer properties, such as, protein aggregation, ${ }^{13}$ host-guest

17 interactions, gene delivery, ${ }^{10,12}$ catalysis, ${ }^{14}$ molecular sensing and controlled drug release. ${ }^{15,16}$

18 The PETIM series of dendrimers is characterized by tertiary amine branch sites, ether linkages,

19 n-propyl spacer and primary amine at their peripheries. ${ }^{17,18}$ Systematic molecular dynamics

20 simulation studies of the structure of PETIM dendrimers illustrated a flexible structure, due to

21 the presence of $n$-propyl spacers with ether linkages. ${ }^{19,20}$ Furthermore, PETIM dendrimers

22 exhibit profound gene vector abilities ${ }^{21-23}$ and hence, a study of the protonation behavior of this

23 series of dendrimers is important. An assessment of the protonation pattern in PETIM 
1 dendrimers was undertaken through the techniques of $\mathrm{pH}$ titrations, ${ }^{1} \mathrm{H}$ and ${ }^{15} \mathrm{~N}$ NMR

2 spectroscopies and theoretical calculations. The mechanism of protonation provided insights to

3 the nucleic acid condensation properties of the dendrimers. The study was extended further so as

4 to determine the buffering capacity of the dendrimers relevant to the endosomal $\mathrm{pH}$ range of 4-6.

5 Experimental Section

6 Amine functionalized PETIM dendrimers of generations 0, 1, 2 and 3 were synthesized

7 according to procedures reported previously. ${ }^{17,18,22}$ Aqueous stock solutions (4 mM) of the

8 amine terminated dendrimers of each generation were prepared by dissolving required amounts

9 G0, G1, G2 and $\mathbf{G 3}$ dendrimers in $10 \mathrm{~mL}$ MilliQ water. Aq. $\mathrm{NaCl}(1 \mathrm{M})$ stock solution and aq.

10 solution of $\mathrm{HCl}(0.3 \mathrm{M})$ were also prepared in MilliQ water. Solutions for titration, at a final

11 concentration of $16 \mathrm{mM}$ of amine in the presence of $150 \mathrm{mM} \mathrm{NaCl}$, were prepared to a final

12 volume of $5 \mathrm{~mL}$ by diluting the required volumes of dendrimer and $\mathrm{NaCl}$ in MilliQ water.

$13 \mathbf{p H}$ titrations. The $\mathrm{pH}$ titration of the dendrimer solutions with aq. $\mathrm{HCl}$ was carried out using a 14 glass electrode, $\mathrm{Ag} / \mathrm{AgCl}$ reference electrode with a salt bridge. Prior to the titration 15 experiments, the instrument was calibrated using standard buffer solutions ( $\mathrm{pH} 4.008,50.0 \mathrm{mM}$ $16 \mathrm{~K}_{2} \mathrm{HPO}_{4} ; \mathrm{pH} 10.012,25.0 \mathrm{mM} \mathrm{Na}_{2} \mathrm{CO}_{3}$ plus $25.0 \mathrm{mM} \mathrm{NaHCO}$ ). All the titrations were carried 17 out at $25 \pm 0.2{ }^{\circ} \mathrm{C}$. Aq. dendrimer solutions at a final concentration of $16 \mathrm{mM}$, in the presence of $150 \mathrm{mM} \mathrm{NaCl}$, were prepared and the initial $\mathrm{pH}$ of the solution was recorded. The solutions were

19 then titrated with aq. $\mathrm{HCl}$ solution $(10 \mu \mathrm{L})$ and $\mathrm{pH}$ was recorded after $60 \mathrm{~s}$ equilibration of the solutions. The titration was continued until $\mathrm{pH}$ 3. The readings obtained were analysed using

21 the software Origin 8. All the titrations were carried out in triplicates and back titrations were 22 performed, in order to validate the reproducibility of the $\mathrm{pH}$ measurements. 
1 NMR titrations. For NMR titrations, a solution of each dendrimer (16 mM) was prepared in

$2 \quad \mathrm{D}_{2} \mathrm{O}(450 \mu \mathrm{L})$ and ${ }^{1} \mathrm{H}$ NMR spectra were recorded at $400 \mathrm{MHz}$ with 1 s delay and accumulation

3 of 4 scans per sample. The dendrimer solutions were then titrated $\mathrm{DCl}(10 \mathrm{~N})$, such that the

4 incremental acid concentration was 0.03 moles per titration. The solutions were homogenized

5 and equilibrated for $60 \mathrm{~s}$ prior to recording of ${ }^{1} \mathrm{H}$ NMR spectra. ${ }^{15} \mathrm{~N}$ NMR spectra were recorded

6 at $40.5 \mathrm{MHz}$ using a $45 \mathrm{~s}$ delay time. Due to the low abundance of ${ }^{15} \mathrm{~N}$ nuclei $(<0.3 \%), 10000$

7 scans for $\mathbf{G 3}\left(\mathbf{N H}_{2}\right)_{24}$ and 3000 scans for $\mathbf{G 1}\left(\mathbf{N H}_{2}\right)_{\mathbf{6}}$ were accumulated for each sample. $\mathrm{CH}_{3} \mathrm{NO}_{2}$

8 was used as an external reference for calibration of the ${ }^{15} \mathrm{~N}$ NMR spectra, which was inserted as

9 a sealed sample in the NMR tube. Chemical shift of the nitrogen atom of $\mathrm{CH}_{3} \mathrm{NO}_{2}(\delta=380.23$

$10 \mathrm{ppm})$ was used to calibrate the spectra. ${ }^{24}$

\section{Results}

13 pH Titrations. PETIM dendrimers, constituted with primary amine functionalities at the 14 peripheries, were synthesized by two iterative Michael addition reactions and two iterative 15 functional group reductions, as described in Scheme $\mathbf{1 .}^{22} \mathrm{~A} \mathrm{pH}$ titration of the amine 16 functionalized dendrimers $\mathbf{G 0}\left(\mathbf{N H}_{2}\right)_{3}, \mathbf{G 1}\left(\mathbf{N H}_{2}\right)_{6}, \mathbf{G} 2\left(\mathbf{N H}_{2}\right)_{12}$ and $\mathbf{G 3}\left(\mathbf{N H}_{2}\right)_{24}$ (Figure 1a) was 17 undertaken to determine the $\mathrm{pH}$ required for complete protonation of the dendrimer amines. 18 Aqueous solutions of the dendrimer $(16 \mathrm{mM})$ in aq. $\mathrm{NaCl}(150 \mathrm{mM})$ were titrated with aq. $\mathrm{HCl}$ $19(0.3 \mathrm{M})$ and the $\mathrm{pH}$ of the solution was measured after $60 \mathrm{~s}$ equilibration (Figure 1b). A first 20 order analysis of the titration curves indicated the equivalence points to be $6.2,6.0,6.5$ and 5.8

21 for dendrimers of generations $0,1,2$, and 3, respectively. The observed changes in $\mathrm{pH}$ of the 22 dendrimer solution, are reversed fully by performing a back-titration with aq. $\mathrm{NaOH}(0.3 \mathrm{M})$ and 
1 thus the protonation-deprotonation profiles are fully reversible (Supporting Information Figure

$2 \mathrm{~S} 1)$. The results indicated that PETIM dendrimers are completely protonated at a $\mathrm{pH}$ of $\sim 6$.

4 NMR titrations. The protonation of primary and tertiary amine sites were probed further 5 through NMR experiments, for which the methylene protons adjacent to the amine moieties and 6 nitrogen nuclei were monitored by ${ }^{1} \mathrm{H}$ and ${ }^{15} \mathrm{~N}$ NMR spectroscopies, respectively.

A $\mathrm{D}_{2} \mathrm{O}$ solution of amine functionalized dendrimer $(16 \mathrm{mM})$ was titrated with $\mathrm{DCl}$ and protons of the methylene groups adjacent to the primary and tertiary amines, labelled ' $a$ ' and ' $b$ ' respectively, were monitored. The solvent residual peak was used as the internal standard. Resulting spectra were plotted as a stack plot and the $\mathrm{pH}$ values were assigned from the corresponding acid mole fraction in the $\mathrm{pH}$ titrations. NMR titration profiles of dendrimers G0(NH $)_{3}$ and $\mathbf{G 1}\left(\mathbf{N H}_{2}\right)_{6}$ are shown in (Figures 2a and 3a). Changes in chemical shifts $(\delta)$ of methylene protons adjacent to nitrogens upon addition of $\mathrm{DCl}$ are shown as a plot of $\delta$ vs the moles of DCl added (Figures $\mathbf{2 b}$ and $\mathbf{3 b}$ ). ${ }^{1} \mathrm{H}$ NMR titrations of $\mathbf{G 2}\left(\mathbf{N H}_{\mathbf{2}}\right)_{\mathbf{1 2}}$ and $\mathbf{G 3}\left(\mathbf{N H}_{2}\right)_{\mathbf{2}}$ and the plot of $\delta v s$ moles of DCl added are shown in Figures 4 and 5. A sharp singlet peak at $\delta 3.19$ ppm corresponded to residual methanol and remained unaffected during the study. Although

17 methylene protons adjacent to oxygens and internal methylene protons of the propyl spacer group also shifted down-field, major changes were observed prominently in ' $a$ ' and ' $b$ ' protons, and thus are discussed further herein.

In general, the methylene proton resonances underwent down-field shift of $\sim 0.45-0.5 \mathrm{ppm}$ upon addition of DCl. Analysis of the chemical shifts showed that methylene protons adjacent to

22 the primary amine moiety, namely 'a', resonating at $\delta \sim 2.6 \mathrm{ppm}$, underwent down-field shift 23 immediately upon addition of $\mathrm{DCl}$, followed by shift of protons adjacent to the tertiary amine 
1 sites, namely, protons ' $b$ ', which appeared initially at $\delta \sim 2.4 \mathrm{ppm}$, in all the dendrimer

2 generations. From these analyses, we infer that tertiary amine protonation is initiated at a $\mathrm{pH}$ at

3 which the primary amines are completely protonated.

${ }^{1} \mathrm{H}$ NMR titrations of the corresponding hydroxyl group terminated dendrimers $\mathbf{G 0}(\mathbf{O H})_{3}$,

5 G1 $(\mathrm{OH})_{6}, \mathbf{G 2}(\mathrm{OH})_{12}$ and $\mathbf{G 3}(\mathrm{OH})_{24}$, were also performed (Figure 6a). These dendrimers do not

6 possess primary amine moieties at their peripheries, unlike amine-terminated dendrimers,

7 whereas the tertiary amine sites are intact in hydroxyl group terminated dendrimers as in the case

8 of $\mathbf{G 0}\left(\mathbf{N H}_{2}\right)_{3}, \mathbf{G 1}\left(\mathbf{N H}_{2}\right)_{6}, \mathbf{G 2}\left(\mathbf{N H}_{2}\right)_{12}$ and $\mathbf{G 3}\left(\mathbf{N H}_{2}\right)_{24}$. Since the hydroxyl group terminated

9 dendrimers contain only the tertiary amines, changes in the resonances correspond to the

10 protonation of the tertiary amines only. Accordingly, dendrimer solutions in $\mathrm{D}_{2} \mathrm{O}(16 \mathrm{mM})$ were

11 titrated with $\mathrm{DCl}(10 \mathrm{~N})$ and the resonances of ${ }^{1} \mathrm{H}$ nucleus was monitored. A representative stack

12 plot of G1(OH) $)_{\mathbf{6}}$ is shown in Figure 6b. The ${ }^{1} \mathrm{H}$ NMR stack plot spectra of $\mathbf{G 0}(\mathbf{O H})_{3}, \mathbf{G 2}(\mathbf{O H})_{12}$

13 and $\mathbf{G 3}(\mathbf{O H})_{\mathbf{2} 4}$ are given in the Supporting Information.

The hydroxyl group terminated dendrimers showed one resonance for the methylene groups

15 adjacent to the tertiary amine moieties, namely ' $b$ ', at $\delta \sim 2.45 \mathrm{ppm}$. Upon the first addition of

$\mathrm{DCl}$, an additional peak emerged, accompanied by a net down-field shift of $\sim 0.6 \mathrm{ppm}$. This

17 change continued with further additions of DCl until the peak at $\delta \sim 2.45 \mathrm{ppm}$ disappeared. This

18 indicated emergence of two types of tertiary amine groups upon protonation. Integration of

19 peaks corresponded to deuteration of peripheral shell tertiary amines (b1) initially, followed by

20 the deuteration of inner shell tertiary amines (b2) (Figure 6b). Plots of moles of DCl vs the

21 chemical shift of methylene protons b1 and b2 of $\mathbf{G 0}(\mathbf{O H})_{3}, \mathbf{G 1}(\mathbf{O H})_{6}, \mathbf{G 2}(\mathbf{O H})_{12}$ and $\mathbf{G 3}(\mathbf{O H})_{24}$

22 dendrimers are shown in Figure 7, from which sharper sigmoidal transition in the case of inner

23 core tertiary amine moieties than that at the peripheries was observed. 
${ }^{15}$ N NMR titrations. The NMR studies were undertaken further by assessing the ${ }^{15} \mathrm{~N}$ chemical

2 shifts of the dendrimers. ${ }^{15} \mathrm{~N}$ NMR spectra of the dendrimers in $\mathrm{D}_{2} \mathrm{O}$ were recorded in $\mathrm{CH}_{3} \mathrm{NO}_{2}$

$3(\delta=380 \mathrm{ppm})$ as the internal standard. ${ }^{24}$ The dendrimer solutions were titrated with $\mathrm{DCl}$ as

4 described previously for the ${ }^{1} \mathrm{H}$ NMR titration study. Initial addition of 0.01 moles of DCl

5 corresponded to the molar equivalent with respect to the molar equivalent of primary amines,

6 whereas subsequent additions of 0.1 mole of $\mathrm{DCl}$, initiated deuteration of the interior tertiary

7 amine sites. ${ }^{15} \mathrm{~N}$ NMR spectra of $\mathbf{G 1}\left(\mathbf{N H}_{2}\right)_{6}$ and $\mathbf{G 3}\left(\mathbf{N H}_{2}\right)_{24}$ were recorded and two distinct

8 resonances, corresponding to primary and tertiary amines at $\sim 21.5 \mathrm{ppm}$ and $41 \mathrm{ppm}$,

9 respectively, were followed (Figure 8). These chemical shifts were assigned on the basis of the

10 corresponding spectra of hydroxyl group functionalized dendrimers that have only the tertiary

11 amine sites, thereby providing only one resonance at $\sim 41.5 \mathrm{ppm}$. The first addition resulted in a

12 down-field shift in the peak of the primary amines by $\sim 4-5 \mathrm{ppm}$, with no observable effect on

13 the resonance corresponding to tertiary nitrogens. Subsequent additions of DCl resulted in $\sim 3-$

144 ppm down-field shift in the tertiary nitrogen resonance, without affecting further shifts in the

15 primary nitrogen nuclei. These observations from ${ }^{15} \mathrm{~N}$ NMR experiments thus reiterated a similar

16 protonation behaviour, as assessed by the ${ }^{1} \mathrm{H}$ NMR titrations, which showed that primary amines

17 undergo protonation initially, followed by protonation of the tertiary amines.

19 Determination of the degree of protonation. Degree of protonation $(\theta)$ was calculated from 20 the experimental $\mathrm{pH}$ data using eq. $1 .^{25}$

$21 \quad \theta=\frac{C_{x}-C_{H^{+}}+C_{H O^{-}}}{C_{N}}$ 
1 where, $C_{x}, C_{H^{+}}$and $C_{\mathrm{OH}^{-}}$are the concentrations of added $\mathrm{HCl}$, free $\mathrm{H}^{+}$and free $\mathrm{OH}^{-}$ions in

2 molL ${ }^{-1}$ calculated at a given $\mathrm{pH}$, respectively. $\mathrm{C}_{N}$ is the total dendrimer amine concentration (16

$3 \mathrm{mM}$ ). A plot of $\theta$ vs $\mathrm{pH}$ for each dendrimer is shown in Figure 9. Analyses of results provided

4 in the figure show that transitions pertaining to G2 and G3 dendrimers are sharper than that for

5 G0 and G1 dendrimers. In addition to prominent changes at $\theta$ values of $0.5-0.6$, much sharper

6 transitions occur at $\theta$ of $0.6-0.85$ to $\mathrm{G} 2$ and G3 generations, within a $\mathrm{pH}$ change of $\sim 0.5$ unit,

7 than that for the remaining two lower generation dendrimers, where $\theta$ values required broader $\mathrm{pH}$

8 change of $\sim 1$ unit. Such a sharp change in $\mathrm{pH}$ as a function of $\theta$ would involve tertiary amine

9 sites that are many more for higher generation dendrimers than that for lower generations. Sharp

$10 \mathrm{pH}$ changes with respect to $\theta$ values prompted us to account tertiary amine sites in Figure 9 for

$11 \mathrm{G} 2$ and G3 generation dendrimers.

12 Determination of $\mathbf{p K}$ values. In order to account for the observed $\mathrm{pH}$ transitions and $\theta$ values,

$13 \mathrm{pK}$ values of the dendrimer amines were calculated from the experimental data and theoretical

14 simulations as described below.

15 The $\mathrm{pK}$ values were calculated from the experimentally determined $\theta$ values using equations 162 and $3 .^{26}$

17

$$
\theta=\frac{1}{N} \frac{\sum_{n=0}^{N} n \bar{K}_{n} z^{n}}{\sum_{n=0}^{N} \bar{K}_{n} z^{n}} \quad \text { for } n=1,2, \ldots N
$$

$$
p K_{n}=\log \left(\bar{K}_{n} / \bar{K}_{n-1}\right) \text { for } n=1,2, \ldots N
$$


1 where, $z$ is the proton activity given by $p H=-\log z, N$ is the number of amine moieties in the

2 dendrimer and $\bar{K}_{n}$ and $\bar{K}_{n-1}$ are the dissociation constants.

For theoretical determination of $\mathrm{pK}$ values, the protonation pattern is considered to be

4 regulated by the interaction of the protonation site with the neighbouring groups, in accordance with the Ising model. ${ }^{25}$ Protonation process leads to amine sites being positively charged, subsequent protonation of remaining amine sites requires consideration of the already protonated sites. This consideration is defined by the pair-interaction parameter $(\varepsilon)$ and is based on the sitebinding model for polyamine systems, as described by Koper and Borkovec. The parameters are illustrated in Figure 10. In the present study, the $\varepsilon$ values are used on the basis of the nearest neighbour interaction analysis formulated by Koper and Borkovec for the polyamine systems, including polyamine dendrimers, with the aid of theoretical simulations. ${ }^{25-28}$ Interaction between the outer shell primary amine and the next shell tertiary amine was assigned a value $\varepsilon_{1}=1.05$, whereas the interactions between all the tertiary amines was assigned $\varepsilon_{2}=1.21$, similar to the assignments made to PPI dendrimers reported previously. ${ }^{28}$ We also included an interaction of dendrimer amines with the linker oxygen ${ }^{29}$ as $\varepsilon_{3}=0.18 .^{26}$ The through-space interactions between the peripheral amine and tertiary amines was assigned a value $\varepsilon_{4}=0.14$, as reported for the PAMAM dendrimers. The $\mathrm{pK}$ values using the pair-interaction parameters was determined using equation $4 .^{25}$

$$
p K=p K_{0}-\log \frac{N+1-n}{n}-\sum \varepsilon
$$

where $\mathrm{N}$ is the total number of amines in dendrimer, $\mathrm{n}=1$ to $\mathrm{N}$ and $\varepsilon$ is the pair-interaction parameter. The $\mathrm{pK}$ values for $\mathbf{G} \mathbf{0}\left(\mathbf{N H}_{2}\right)_{3}$ and $\mathbf{G 1}\left(\mathbf{N H}_{2}\right)_{6}$, having four and ten nitrogens, 
1 respectively, were determined using the pair-interaction parameters. The experimentally derived

$2 \quad \mathrm{pK}_{\mathrm{n}}$ values according to equation 3 and that derived theoretically through equation 4 are given in

3 Table 1. The experimental and theoretical assessments show that the values are in agreement

4 with each other, with which we infer that the protonations occur stepwise, from outer-to-inner

5 shell of the dendrimer structure. This inference is discussed in detail in a section below.

7 Determination of buffering capacities. The protonation behaviour of dendrimers provides

8 valuable information their buffering capacities (BC) and ability to effect endosomal escape, 9 relevant to efficient gene delivery. ${ }^{30}$ The $\mathrm{BC}$ were thus derived from the $\mathrm{pH}$ titration data of the amine dendrimers using equation 5, as described by Buschmann and co-workers. ${ }^{31}$

$$
B C=-\frac{d n_{H C l}}{d p H} \times \frac{1}{n_{N}}
$$

12 where, $n_{\mathrm{HCl}}$ and $n_{N}$ are the number of moles of $\mathrm{HCl}$ added and the total moles of amine in 13 solution, respectively.

14 A plot of the buffering capacity of the dendrimer $v s \mathrm{pH}$ is shown in Figure 11. A major observation is that the buffering capacity of the dendrimers increases with increasing dendrimer generation. A high $\mathrm{BC}$ indicates that larger amount of acid is required in order to protonate amines at a given $\mathrm{pH}$. At physiological $\mathrm{pH}$, a high $\mathrm{BC}$ assumes importance, as it implies the phenomenon of proton-sponge mechanism for endosomal escape. ${ }^{32}$

\section{Discussion}

The influence of $\mathrm{pH}$-variation on the dendrimer structure, exemplified by phenomena such

22 as 'swelling-shrinking' and 'back-folding' demonstrate the importance of acid-base properties of 
1 dendrimers in drug encapsulation, delivery and molecular sensing. ${ }^{33-35}$ Thus, a study of

2 protonation behaviour of polycationic vectors, and hence PETIM dendrimers assumes

3 importance.

4 The protonation pattern of PAMAM and PPI dendrimers and branched polymers were 5 reported previously. ${ }^{26,36}$ In these studies, the $\mathrm{pH}$ or potentiometric titrations were combined 6 further with theoretical treatment using the Ising model. It was concluded that PAMAM 7 dendrimer would undergo a stepwise protonation, in which the first protonation step involved 8 protonation of all terminal primary amine groups $\left(\mathrm{pK}_{\mathrm{a}} \sim 9\right)$, between $\mathrm{pH}$ of 7 and 8 . This was 9 followed by protonation at $\mathrm{pH} 3-5$, of all the internal tertiary amines $\left(\mathrm{pK}_{\mathrm{a}} 5.8\right)$, with the 10 exception of the core nitrogen. The central core nitrogen was protonated only at very low $\mathrm{pH}$ 11 and was calculated to have a $\mathrm{pK}_{\mathrm{a}}$ value of 3.5. On the other hand, a detailed study of PPI 12 dendrimers by ${ }^{15} \mathrm{~N}$ NMR spectroscopy, potentiometric titrations and simulations showed that all 13 the odd shells protonated in the first instance, followed by protonation of the even shells. ${ }^{36}$ This 14 protonation behaviour, described as "onion shell" like behaviour, showed that primary and 15 tertiary amines in alternate shells of PPI dendrimer have similar $\mathrm{pK}_{\mathrm{a}}$ values. Two-thirds of the 16 nitrogens were protonated at $\mathrm{pH} 10$ and the remaining nitrogens, with $\mathrm{pK}_{\mathrm{a}}$ of 6 , were protonated 17 at $\mathrm{pH} \sim 5 .^{37}$

18 The titration of amine moieties of PETIM dendrimers with an acid followed a sigmoidal 19 transition, that confirmed to the characteristic sigmoidal transitions obtained upon protonation of 20 polyelectrolyte solutions, such as, PEI, chitosan and dendrimers. ${ }^{6,31}$ Further, the fully reversible 21 nature of the titration curves, as verified by the back-titration experiments, indicated that 22 dendrimer-dendrimer interactions are negligible. 
Having established the protonation of dendrimer nitrogens with acid by $\mathrm{pH}$ titration, NMR titrations studies were performed in order to gain insights into the protonation pattern at a molecular level. NMR chemical shifts are sensitive to changes in chemical environment and thus provide a method to assess the protonation pattern. The ${ }^{15} \mathrm{~N}$ NMR chemical shifts of PPI dendrimers of generations 1 to 3 were studied earlier to deduce protonation pattern of this class of dendrimer, which showed distinct peaks for nitrogens of each shell. An alternate shell protonation model for PPI dendrimers was proposed on the basis of ${ }^{15} \mathrm{~N}$ NMR chemical shifts. ${ }^{36}$ ${ }^{15} \mathrm{~N}$ NMR spectrum of PETIM dendrimers studied herein showed only two peaks, corresponding to the primary amine nitrogens at $\sim 21 \mathrm{ppm}$ and tertiary amine nitrogens at $41 \mathrm{ppm}$. These two chemical shifts indicated two distinct chemical environments, one at the periphery and the second at the dendrimer interior. Each shell nitrogen underwent distinct shifts upon the addition of acid (Figure 8). From the observed chemical shifts, it is inferred that outer-shell primary amines are protonated first followed by the protonation of the inner-shell tertiary amines, at $\mathrm{pH}$ values as given in Figure 12.

Upon increasing the proton concentration of an aq. dendrimer solution, the outer shell primary amines are protonated initially. The protonation state in which all the peripheral primary amines are protonated leads to the formation of a stable species, which is reflected in the plateau at degree of protonation, $\theta \sim 0.6-0.7$ in the titration curve (Figure 9). This species is found to exist at $\mathrm{pH} \sim 9$. Protonation of primary amines is followed by the protonation of penultimate shell tertiary amines. The core nitrogen is the last to undergo protonation at acidic $\mathrm{pH}$ of $\sim 4-4.5$. This protonation pattern was further verified by calculating the $\mathrm{pK}$ values from experimental data, as well as, Ising model equations. Calculation of $\mathrm{pK}$ values using Ising model required the use of different pair interaction parameters $(\varepsilon)$. In addition to the interactions 
1 between the primary amine and tertiary amines, the ether-amine interactions and through-space

2 interactions between the peripheral amines and tertiary amines were also included to account for

3 the flexibility and back-folding phenomena observed in PETIM dendrimer. ${ }^{19}$

4 From the above studies, the protonation behaviour of PETIM dendrimers is summarized as

5 follows: (i) the degree of protonation exhibits a major transition at $\theta \sim 0.45-0.6$, indicating a

6 differing protonation behaviour of primary and tertiary amines; (ii) minor transitions at $\theta \sim 0.8$

7 and 0.9 indicate differential protonation of tertiary amines; (iii) protonation of interior amines

8 prior to complete protonation of the preceding shell was unfavourable due to the larger pair

9 interaction energies; (iv) $\mathrm{pK}$ values of the dendrimer amines, calculated using the Ising model,

10 are in good agreement with the experimental values and showed a distinct $\mathrm{pK}$ value range for

11 nitrogens in each shell.

12 The unique shell-wise protonation pattern of PETIM dendrimers was extended to its 13 applicability as gene delivery vectors. Study of the protonation behaviour of PAMAM 14 dendrimers showed that only the primary amines are protonated at physiological $\mathrm{pH}$. The 15 tertiary amines which undergo protonation at acidic $\mathrm{pH}$ were shown to affect the endosomal 16 escape via the proton-sponge mechanism. ${ }^{9}$ On the other hand, both primary and tertiary amines

17 in PPI dendrimers participated in nucleic acid condensation due to the alternate-shell protonation

18 pattern. $^{38}$ The difference in protonation pattern was evident in the gene transfection efficiencies

19 of these dendrimers. Complexes formed with PAMAM dendrimers through interactions with 20 primary amines were easily accessible to transcription factors and resulted in higher gene 21 transfections, in comparison to the tight complexes formed by PPI dendrimer. ${ }^{39}$ The importance

22 of dendrimer flexibility to the formation of stable complexes was also demonstrated using lower 23 generation modified PAMAM dendrimers for siRNA delivery. ${ }^{40}$ 
The PETIM dendrimers, $\mathbf{G 2}\left(\mathbf{N H}_{\mathbf{2}}\right)_{\mathbf{1 2}}$ and $\mathbf{G 3}\left(\mathbf{N H}_{\mathbf{2}}\right)_{\mathbf{2} 4}$, showed a good buffering at the $\mathrm{pH}$ range of $4-6$ in the presence of $150 \mathrm{mM} \mathrm{NaCl}$. This observation indicated that amine moieties in PETIM dendrimer of higher generations could efficiently aid endosomal escape, through the protonation of the inner shell tertiary amines. The effective endosomal escape properties of the dendrimer are evident from previous studies, wherein, the addition of the lysomotropic agent, chloroquine did not lead to enhanced transfection. ${ }^{22}$ It was postulated that the dendrimer amines are sufficient to enable endosomal escape and did not require an additional reagent. The studies of buffering capacity of $\mathbf{G 3}\left(\mathbf{N H}_{2}\right)_{\mathbf{2}}$ presented in this work help to ascertain this hypothesis. Further, the protonation studies showed that the primary amines, as well as, the penultimate shell tertiary amines of the dendrimer are protonated at the physiological $\mathrm{pH}$ and can participate in nucleic acid condensation via electrostatic interactions. The increased number of ionic sites would, in turn, require the use of lesser amounts of dendrimer for nucleic acid condensation, in comparison to PAMAM dendrimers with similar number of peripheral primary amine sites.

\section{Conclusion}

The influence of protonation of amine moieties of the polycationic vectors in modulating critical properties related to their application in biology is relevant, yet underexplored. The study of the protonation behaviour is a critical parameter to develop a synthetic vector as a suitable gene delivery agent. Whereas theoretical simulations and experimental details of protonation behaviour of synthetic polycationic vectors were studied earlier, ${ }^{6,41,42}$ there are only very few reports that document the direct applicability of the protonation behaviour of dendritic macromolecular gene delivery vectors. In this context, the newly developed poly(propyl ether imine) (PETIM) dendritic gene delivery vectors of generations G0 - G3 were evaluated herein 
1 for their protonation behaviour. Initial $\mathrm{pH}$ titrations show that at $\mathrm{pH}$ of $\sim 10$, the outermost shell

2 primary amines are protonated. As the $\mathrm{pH}$ is lowered, the inner shell tertiary amines are

3 protonated periodically, in a shell-wise fashion. The protonation constant for each of the inner

4 shell tertiary amines decreases progressively between $\mathrm{pH} 9.5$ and 6 . The central core amine is

5 the last to protonate, at a $\mathrm{pH} \sim 4.5-5$. This protonation pattern, where the primary amines are

6 protonated faster, followed by the sequential shell-wise protonation of tertiary amines, is studied

7 in detail subsequently by ${ }^{1} \mathrm{H},{ }^{15} \mathrm{~N}$ NMR spectroscopies and theoretical calculation of the $\mathrm{pK}$

8 values using the Ising model. The protonation pattern shows a high buffering capacity of higher

9 generation dendrimer, in the $\mathrm{pH}$ range of $4-6$. This high buffering capacity of the higher

10 generation dendrimer, in turn, enables more efficient gene delivery vector properties. The

11 studies presented herein demonstrate the applicability of PETIM dendritic vectors to the nucleic

12 acid condensation and endosomal escape properties at the physiological $\mathrm{pH}$ range of 4-8, 13 relevant to the gene transfection protocols.

\section{Supporting Information}

16 Supporting Information is available in ESI format

\section{Acknowledgements}

19 We are grateful to the Department of Science and Technology, New Delhi, India, for the 20 financial support. Council for Scientific and Industrial Research (CSIR), New Delhi, is 21 acknowledged for a research fellowship to AL. 


\section{$1 \quad$ References}

2 (1) Turrin, C.-O.; Caminade, A. -M. in Dendrimers: Towards Catalytic, Material and Nicot, B.), John Wiley \& Sons, Ltd, Chichester, UK, 2011, Ch. 17.

(2) Lächelt, U.; Wagner, E. Chem. Rev. 2015, 115, 11043.

Biomedical Uses (Eds: Caminade, A.-M.; Turrin, C.-O.; Laurent, R.; Ouali, A.; Delavaux-

(3) Merkel, O. M.; Mintzer, M. A.; Librizzi, D.; Samsonova, O.; Dicke, T.; Spoat, B.; Gran, H.; Barth, P. J.; Simanek, E. E.; Kissel, T. Mol. Pharmaceutics 2010, 7, 969.

(4) Shi, J.; Schellinger, J. G.; Johnson, R. N.; Choi, J. L.; Chou, B.; Anghel, E. L.; Pun, S. H. Biomacromolecules 2013, 14, 1961.

(5) Dorris, A. C.; Douglas, K. L.; Tabrizian, M.; Barrett, C. J. Canadian J. Chem. 2008, 86, 1085.

(6) Draghici, B.; Ilies, M. A. J. Med. Chem. 2015, 58, 4091.

(7) Filipe, L. C. S.; Campos, S. R. R.; Machuqueiro, M.; Darbre, T.; Baptista, A. M. J. Phys. Chem. B 2016, 120, 10138.

(8) Freeman, E. C.; Weiland, L. M.; Meng, W. S. J. Biomat. Sci., Polymer Edn. 2013, 24, 398.

(9) Koper, G. J. M.; Borkovec, M. Polymer 2010, 51, 5649.

(10) Liu, X.; Zhou, J.; Yu, T.; Chen, C.; Cheng, Q.; Sengupta, K.; Huang, Y.; Li, H.; Liu, C.; Wang, Y.; Posocco, P.; Wang, M.; Cui, Q.; Giorgio, S.; Fermeglia, M.; Qu, F.; Pricl, S.; Shi, Y.; Liang, Z.; Rocchi, P.; Rossi, J. J.; Peng, L. Angew. Chem. Int. Ed. 2014, 53, 11822.

(11) Filion, D.; Lavertu, M.; Buschmann, M. D. Biomacromolecules 2007, 8, 3224.

(12) Liu, Y.; Reineke, T. M. Bioconjugate Chem. 2007, 18, 19.

(13) Klajnert, B.; Cladera, J.; Bryszewska, M. Biomacromolecules 2006, 7, 2186.

(14) Pande, S.; Crooks, R. M. Langmuir 2011, 27, 9609. 
1 (15) Wang, M.; Gong, X.; Hu, J.; Yu, Y.; Chen, Q.; Cheng, Y. J. Phys. Chem. B 2011, 115,

2 12728.

(16) Maingi, V.; Kumar, M. V. S.; Maiti, P. K. J. Phys. Chem. B 2012, 116, 4370.

(17) Krishna, T. R.; Jayaraman, N. J. Org. Chem. 2003, 68, 9694.

(18) Jayamurugan, G.; Jayaraman, N. Tetrahedron 2006, 62, 9582.

(19) Jana, C.; Jayamurugan, G.; Ganapathy, R.; Maiti, P. K.; Jayaraman, N.; Sood, A. K. J. Chem. Phys. 2006, 124, 204719.

(20) Kanchi, S.; Suresh, G.; Priyakumar, U. D.; Ayappa, K. G.; Maiti, P. K. J. Phys. Chem. B 2015, 119, 12990.

(21) Thankappan, U. P.; Madhusudana, S. M.; Desai, A.; Jayamuragan, G.; Rajesh, Y. B. R. D.; Jayaraman, N. Bioconjugate Chem. 2011, 22, 115.

(22) Lakshminarayanan, A.; Ravi, V. K.; Tatineni, R.; Rajesh, Y. B. R. D.; Maingi, V.; Vasu, K. V.; Madhusudhan, N.; Maiti, P. K.; Sood, A. K.; Das, S.; Jayaraman, N. Bioconjugate Chem. 2013, 24, 1612.

(23) Lakshminarayanan, A.; Reddy, B. U.; Raghav, N.; Ravi, V. K.; Kumar, A.; Maiti, P. K.; Sood, A. K.; Jayaraman, N.; Das, S. Nanoscale 2015, 7, 16921.

(24) Srinivasan, P. R.; Lichter, R. L. J. Magn. Reson. 1997, 28, 227.

(25) Smits, R. G.; Koper, G. J. M.; Mandel, M. J. Phys. Chem. 1993, 97, 5745.

(26) Cakara, D.; Kleimann, J.; Borkovec, M. Macromolecules 2003, 36, 4201.

(27) Koper, G. J. M.; Borkovec, M. Polymer 2010, 51, 5649.

(28) Koper, G. J. M.; van Duijvenbode, R. C.; Stam, D. D. P. W.; Steuerle, U.; Borkovec, M. Macromolecules 2003, 36, 2500.

(29) Jayamurugan, G.; Umesh, C. P.; Jayaraman, N. Org. Lett. 2008, 10, 9. 
1 (30) Liu, X.; Wu, J.; Yammine, M.; Zhou, J.; Posocco, P.; Viel, S.; Liu, C.; Ziarelli, F.; Fermeglia, M.; Pricl, S.; Victorero, G.; Nguyen, C.; Erbacher, P.; Behr, J. -P.; Peng, L. Bioconjugate Chem. 2011, 22, 2461.

(31) Richard, I.; Thibault, M.; De Crescenzo, G.; Buschmann, M. D.; Lavertu, M. Biomacromolecules 2013, 14, 1732.

(32) Pack, D. W.; Hoffman, A. S.; Pun, S.; Stayton, P. S. Nat. Rev. Drug Discov. 2005, 4, 518.

(33) Koper, G. J. M.; van Genderen, M. H. P.; Elissen-Román, C.; Baars, M. W. P. L.; Meijer, E. W.; Borkovec, M. J. Am. Chem. Soc. 1997, 119, 6512.

(34) Van Duijvenbode, R. C.; Borkovec, M.; Koper, G. J. M. Polymer 1998, 39, 2657.

(35) Bazzicalupi, C.; Bianchi, A.; Giorgi, C.; Savastano, C.; Morales-Lara, F. Chem. Commun. 2015, 51, 3907 .

(36) Welch, P.; Mutukumar, M. Macromolecules, 1998, 31, 5892.

(37) Maiti, P. K.; Çă̆ın, T.; Lin, S. -T.; Goddard III, W. A. Macromolecules 2005, 38, 979.

(38) Zinselmeyer, B. H.; Mackay, S. P.; Schatzlein, A. G.; Uchegbu, I. F. Pharm. Res. 2002, 19, 960.

(39) Bielinska, A. U.; Kukowska-Latallo, J. F.; Baker, J. R. Biochim. Biophys. Acta 1997, 1353, 180.

(40) Sharma, R.; Zhang, I.; Shiao, T. C.; Pavan, G. M.; Maysinger, D.; Roy, R. Nanoscale 2016, 5106.

(41) Lee, H.; Son, S. H.; Sharma, R.; Won, Y.-Y. J. Phys. Chem. B 2011, 115, 844.

(42) Ziebarth, J. D.; Wang, Y. Biomacromolecules 2010, 11, 29. 


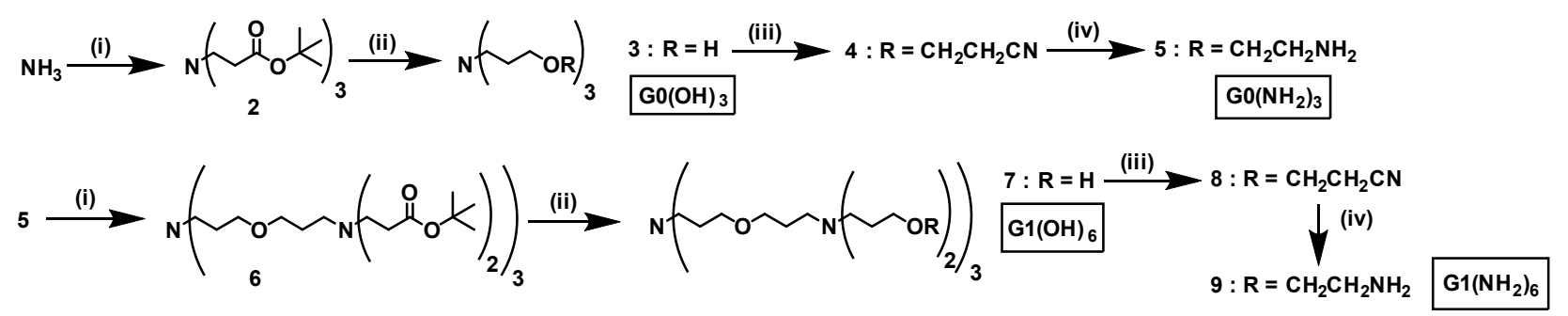

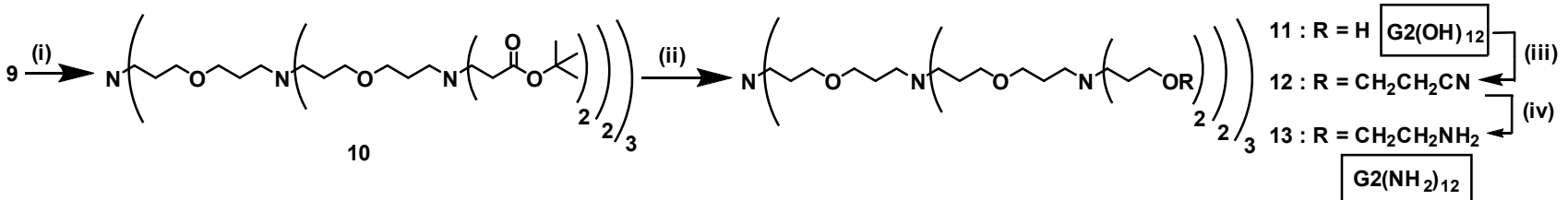

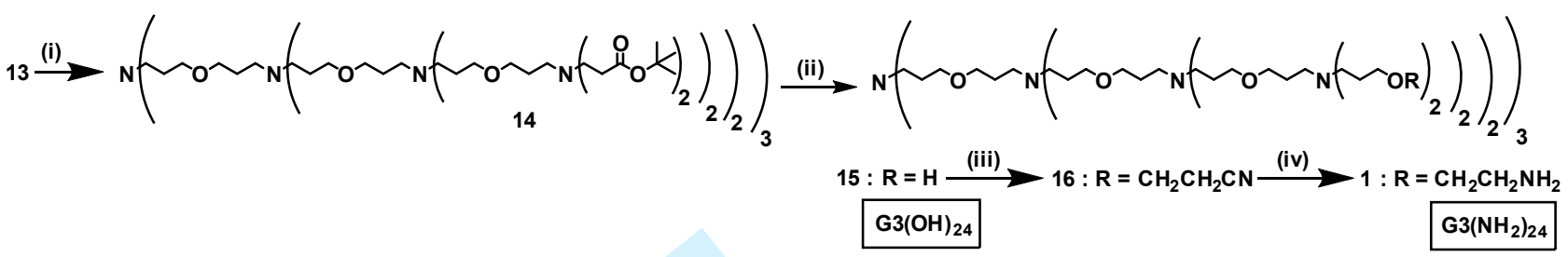

Scheme 1. Reagents and conditions: (i) t-Butyl acrylate, $\mathrm{MeOH}, 36 \mathrm{~h}$; (ii) $\mathrm{LiAlH}_{4}, \mathrm{THF}, 0{ }^{\circ} \mathrm{C}-$ rt, 4 h; (iii) Acrylonitrile, aq. $\mathrm{NaOH}, 48$ h; (iv) Raney Co, $\mathrm{H}_{2}, \mathrm{H}_{2} \mathrm{O}, 70{ }^{\circ} \mathrm{C}, 2 \mathrm{~h}$, quantitative. ${ }^{17.18}$

a)

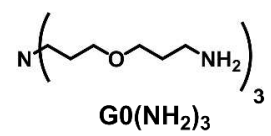<smiles>CC(C)N(C)CCOCCN(C)CCOCCOCCN</smiles>

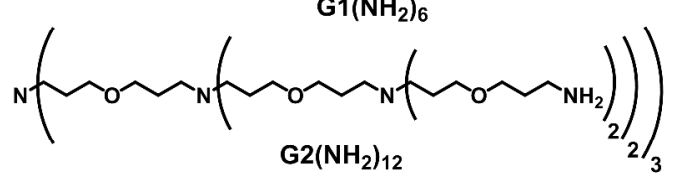

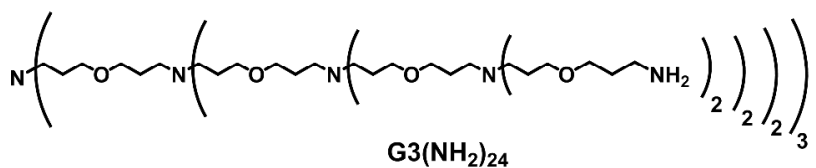

b)

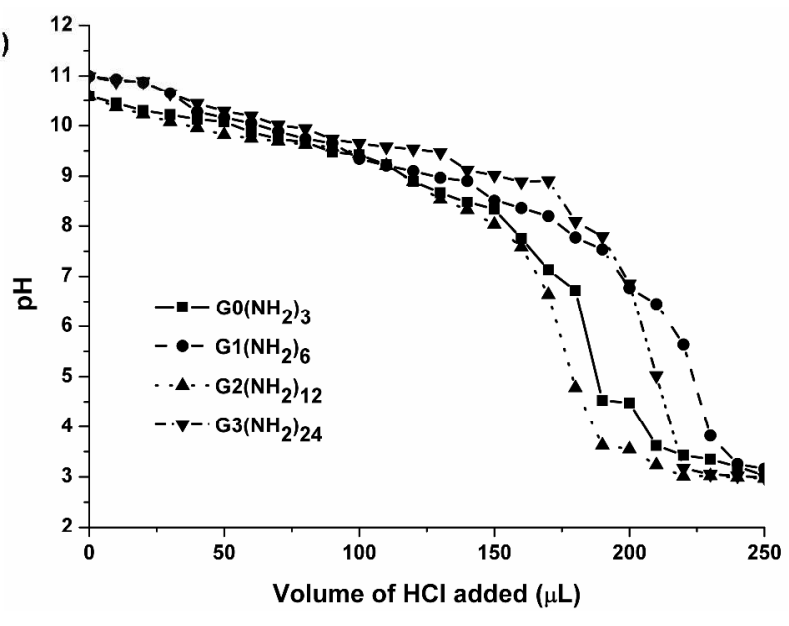

Figure 1. (a) Molecular structures of PETIM dendrimers of generations 0 to 3; (b) change in $\mathrm{pH}$

9 of the aq. dendrimer solution $(16 \mathrm{mM})$ upon addition of aq. $\mathrm{HCl}(0.3 \mathrm{M})$. 
a)

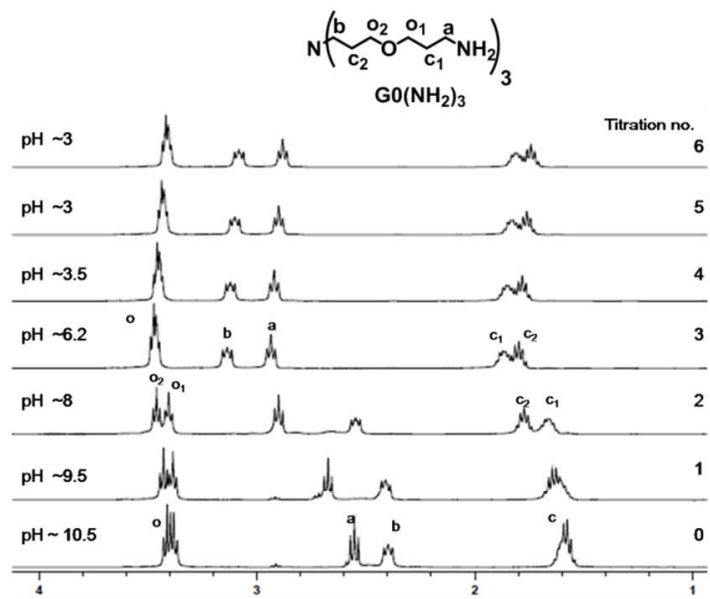

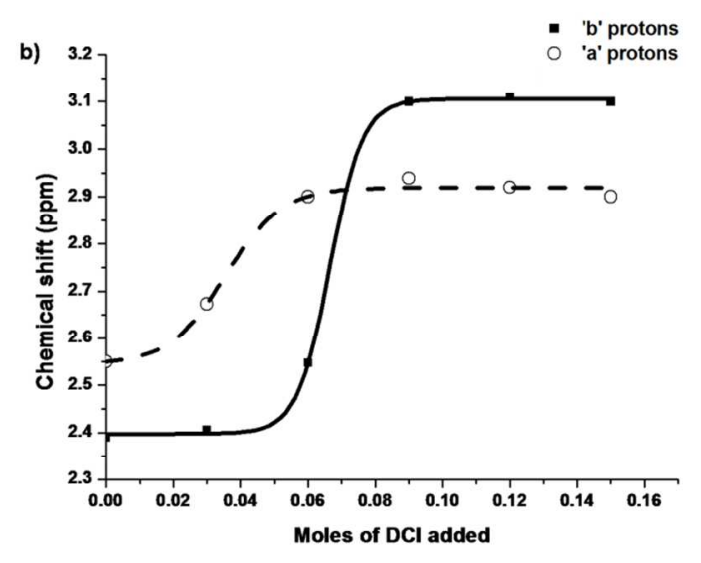

2 Figure 2. (a) Stack plot of ${ }^{1} \mathrm{H}$ NMR $\left(400 \mathrm{MHz}, \mathrm{D}_{2} \mathrm{O}\right)$ spectra and (b) plot of $\delta$ vs the moles of 3 DCl added, along with sigmoidal fit (solid lines) for $\mathbf{G 0}\left(\mathbf{N H}_{2}\right)_{3}$.

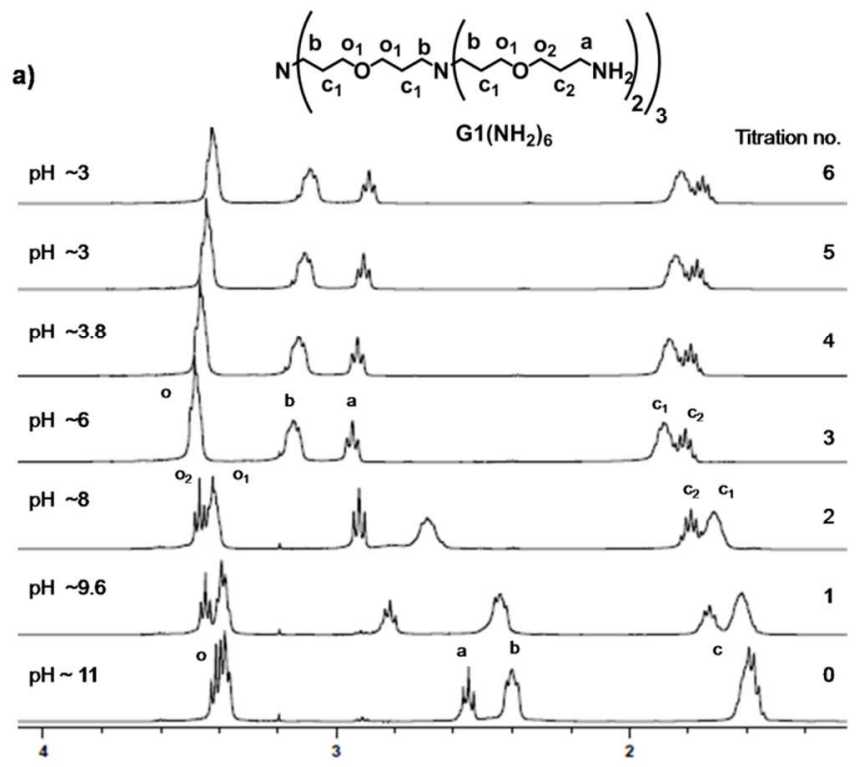

b)

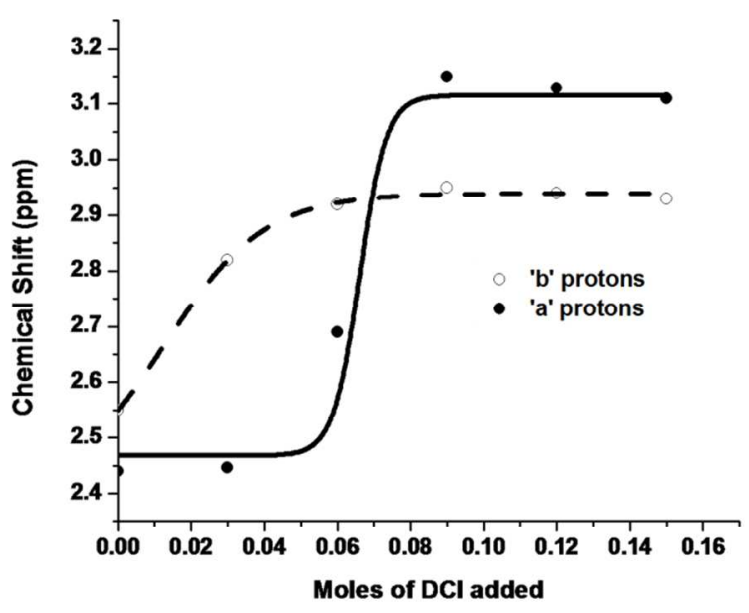

5 Figure 3. (a) Stack plot of ${ }^{1} \mathrm{H}$ NMR $\left(400 \mathrm{MHz}, \mathrm{D}_{2} \mathrm{O}\right)$ spectra and (b) plot of $\delta$ ss the moles of 6 DCl added, along with sigmoidal fit (solid lines) for $\mathbf{G 1}\left(\mathbf{N H}_{2}\right)_{6}$. 
a)

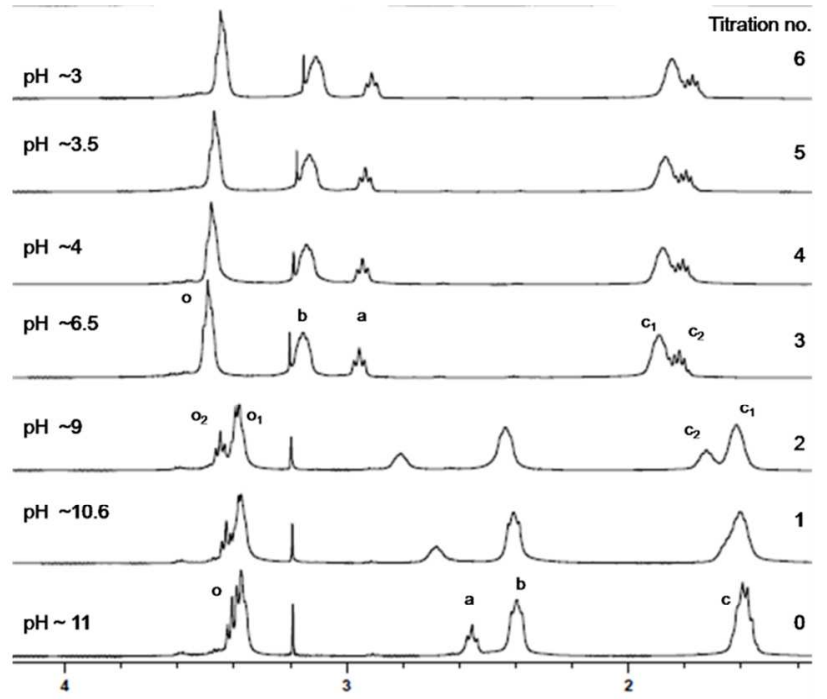

b)

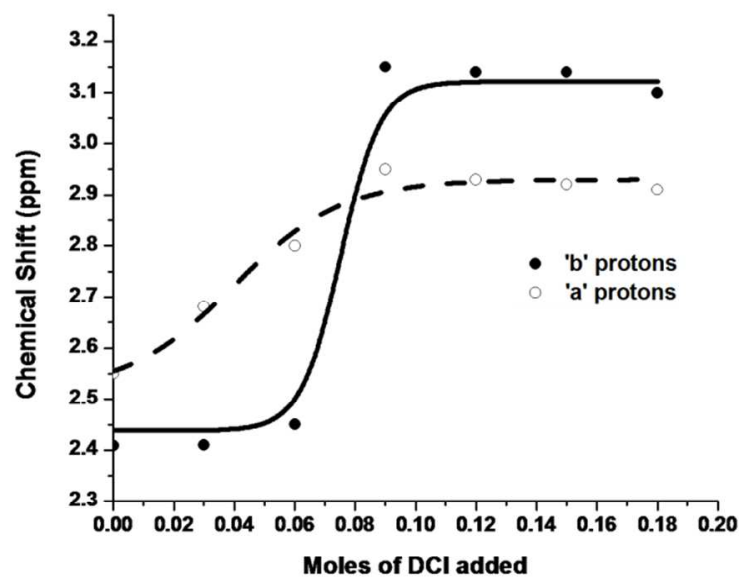

Figure 4. (a) Stack plot of ${ }^{1} \mathrm{H}$ NMR $\left(400 \mathrm{MHz}, \mathrm{D}_{2} \mathrm{O}\right)$ and (b) plot of $\delta$ vs the moles of DCl added, along with sigmoidal fit (solid lines) for $\mathbf{G} \mathbf{2}\left(\mathbf{N H}_{\mathbf{2}}\right)_{\mathbf{1 2}}$.
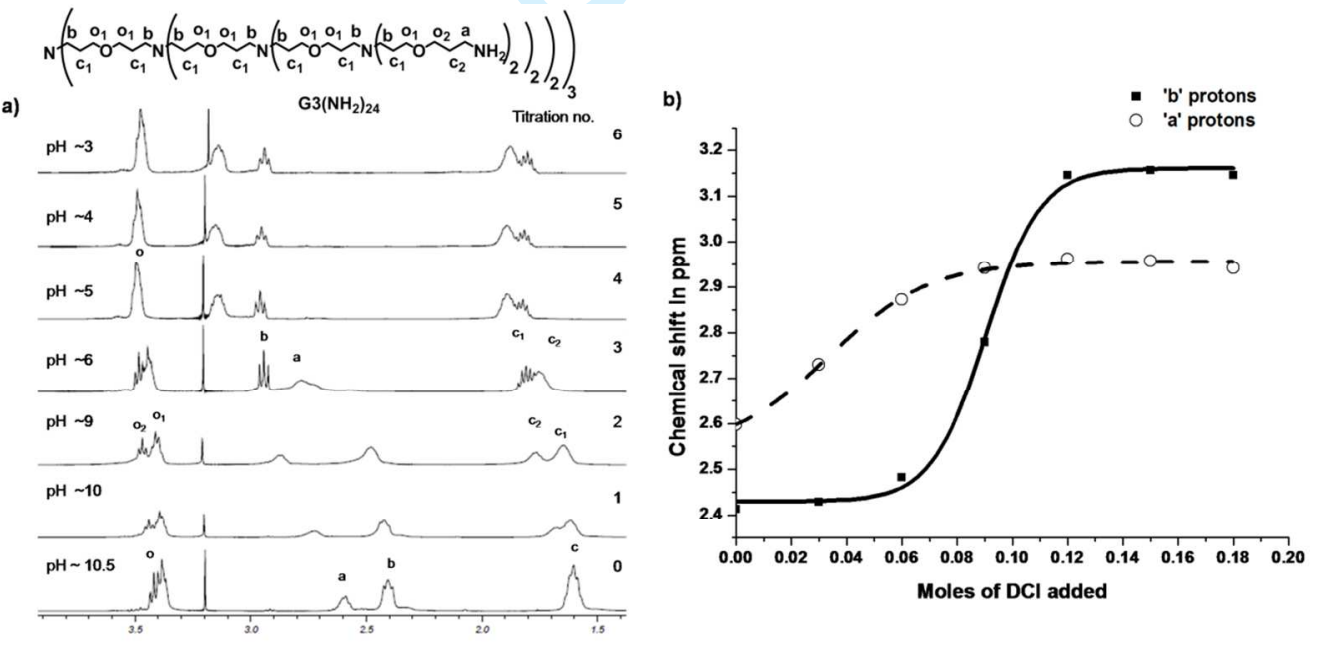

6 Figure 5. (a) Stack plot of ${ }^{1} \mathrm{H}$ NMR $\left(400 \mathrm{MHz}, \mathrm{D}_{2} \mathrm{O}\right)$ spectra and (b) plot of $\delta$ vs the moles of 7 DCl added, along with sigmoidal fit (solid lines) for $\mathbf{G 3}\left(\mathbf{N H}_{2}\right)_{\mathbf{2 4}}$. 

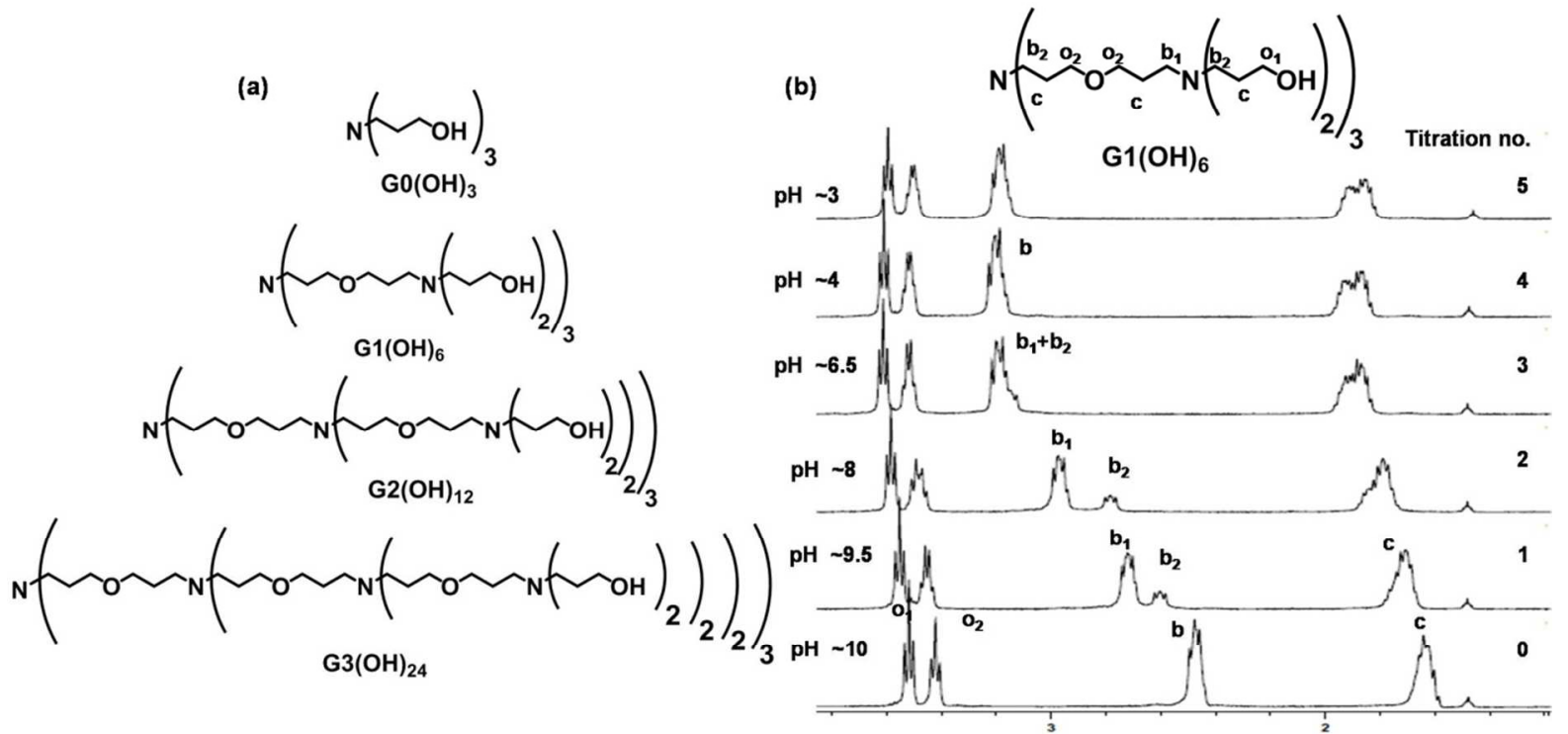

1

2 Figure 6. (a) Molecular structures of PETIM dendrimers of generations 0 to 3: $\mathbf{G 0}(\mathbf{O H})_{\mathbf{3}}$;

3 G1(OH) $)_{6} ; \mathbf{G 2}(\mathrm{OH})_{12}$ and $\mathbf{G 3}(\mathrm{OH})_{24}$. (b) Stack plot of ${ }^{1} \mathrm{H}$ NMR $\left(400 \mathrm{MHz}, \mathrm{D}_{2} \mathrm{O}\right)$ spectra of $4 \mathrm{G1}(\mathrm{OH})_{6}$. 


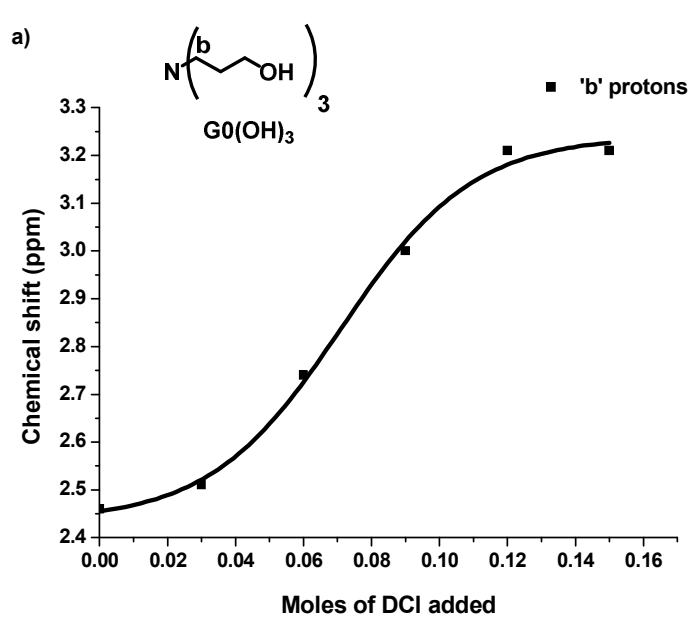

b)

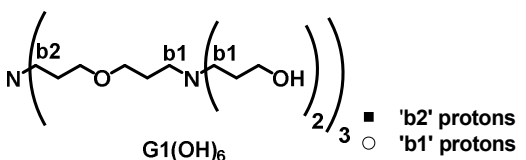

c)
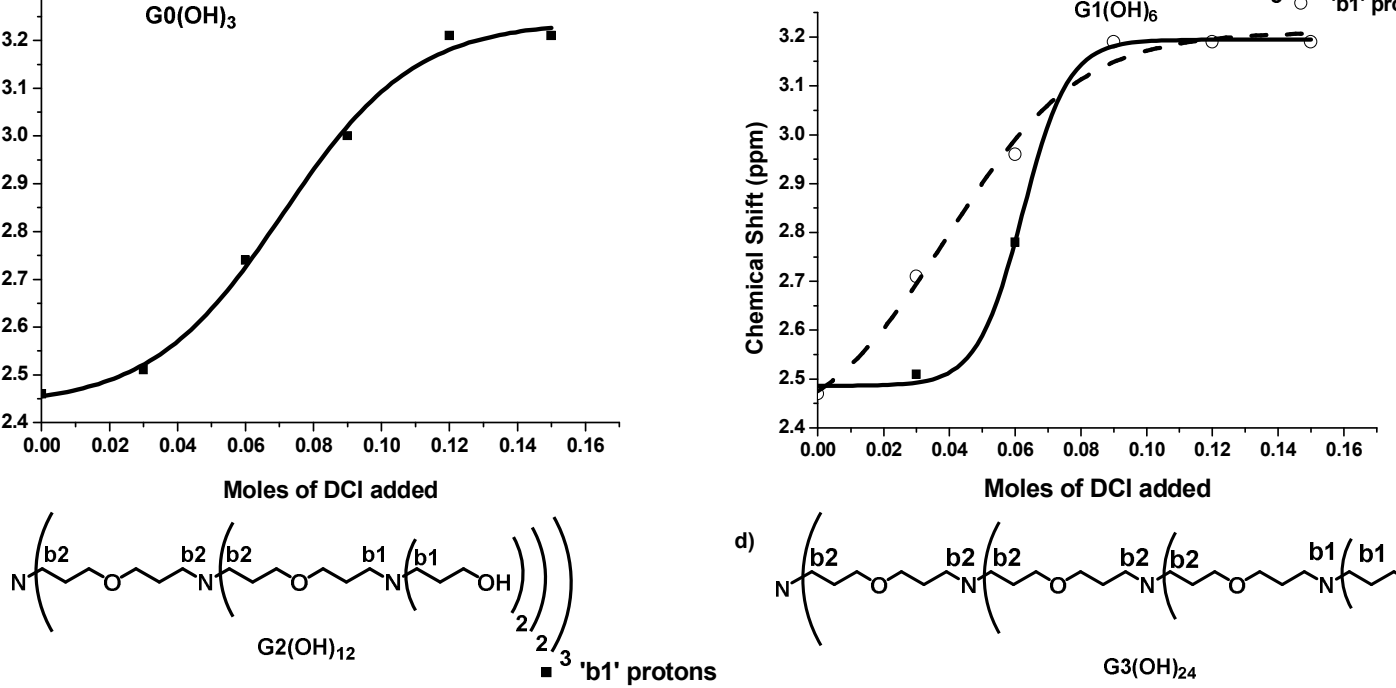

d)
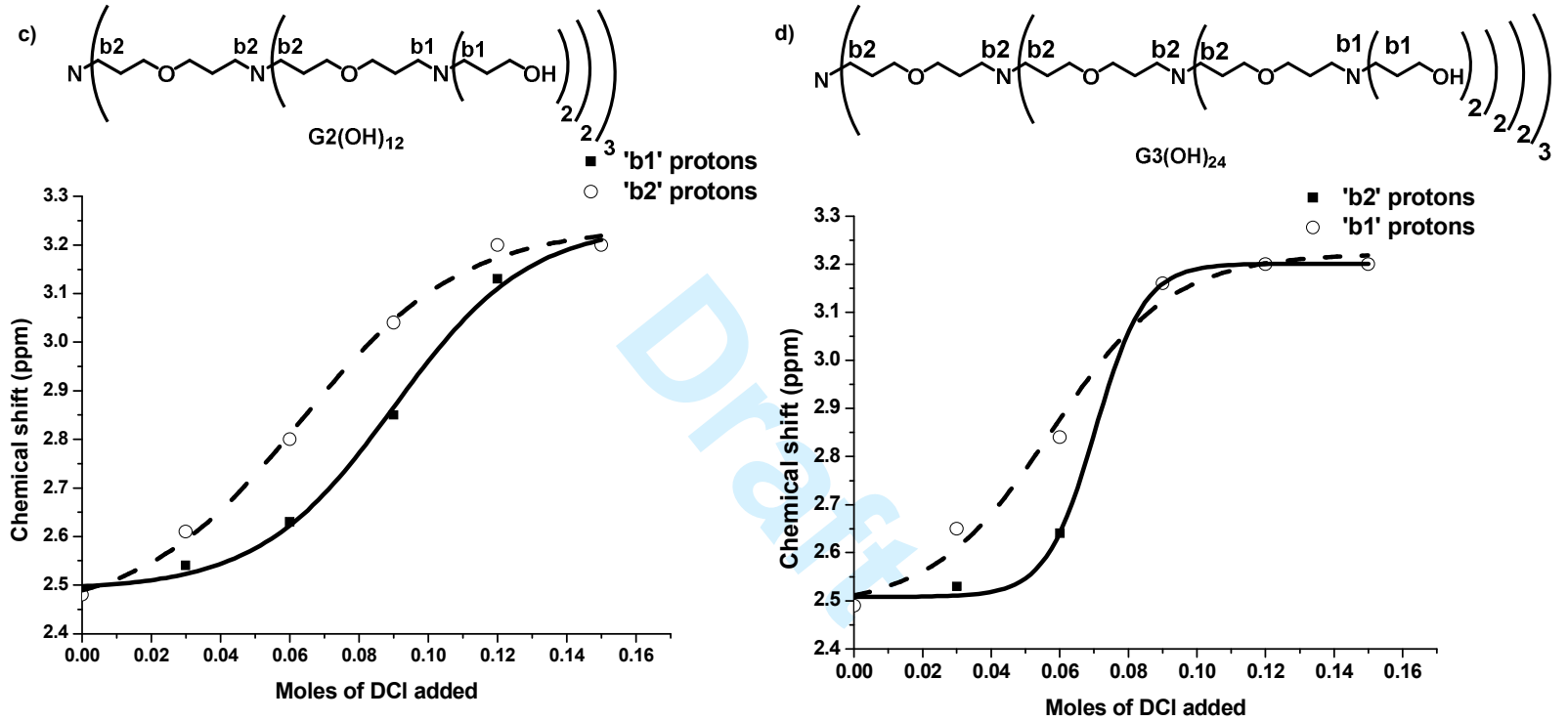

2 Figure 7. Plots of moles of $\mathrm{DCl} v s$ chemical shifts of protons 'b' in(a) $\mathbf{G 0}(\mathbf{O H})_{3}$; (b) $\mathbf{G 1}(\mathbf{O H})_{6}$;

$3 \quad$ (c) $\mathbf{G 2}(\mathbf{O H})_{12}$ and $(\mathrm{d}) \mathbf{G 3}(\mathbf{O H})_{24}$. 

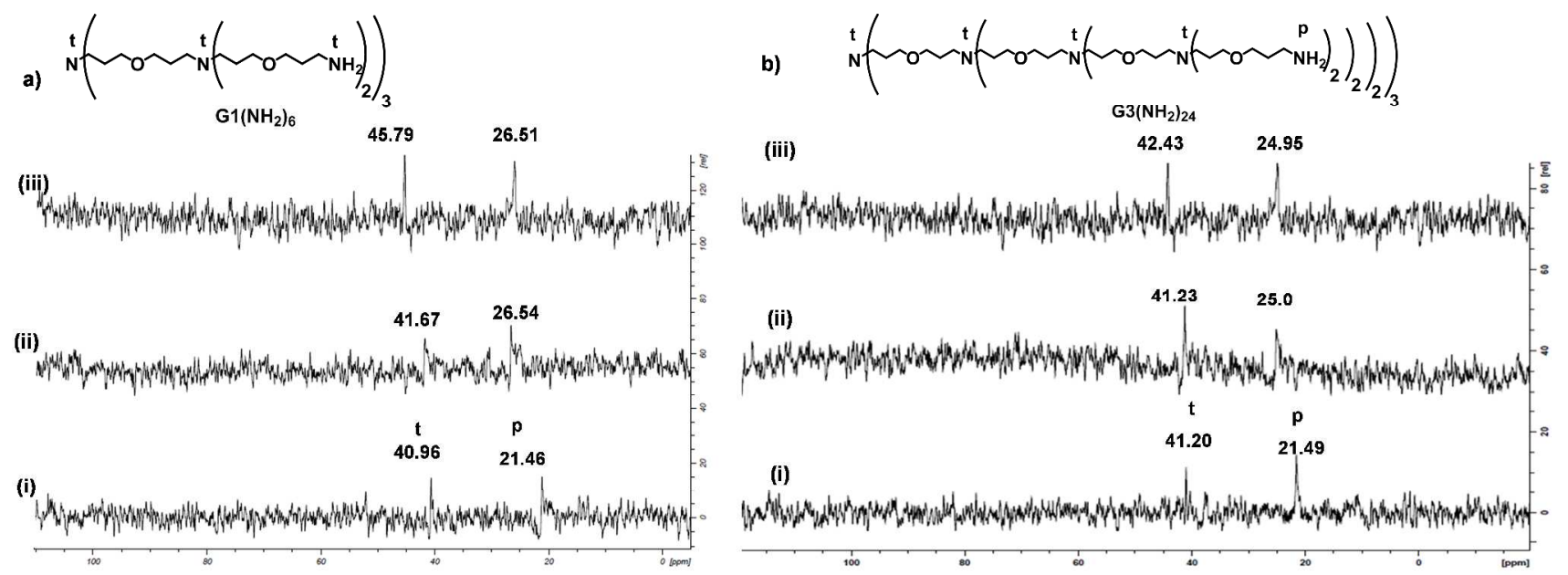

Figure 8. ${ }^{15} \mathrm{~N}$ NMR spectra of (a) $\mathbf{G 1}\left(\mathbf{N H}_{2}\right)_{\mathbf{6}}$ and (b) $\mathbf{G 3}\left(\mathbf{N H}_{2}\right)_{\mathbf{2}}$ in $\mathrm{D}_{2} \mathrm{O}(40.5 \mathrm{MHz})$ : dendrimer without addition of the acid, $\mathrm{pH} \sim 11$; (ii) and (iii) dendrimer sample upon titration 4 with $\mathrm{DCl}, \mathrm{pH} \sim 9$ and 4 , respectively.
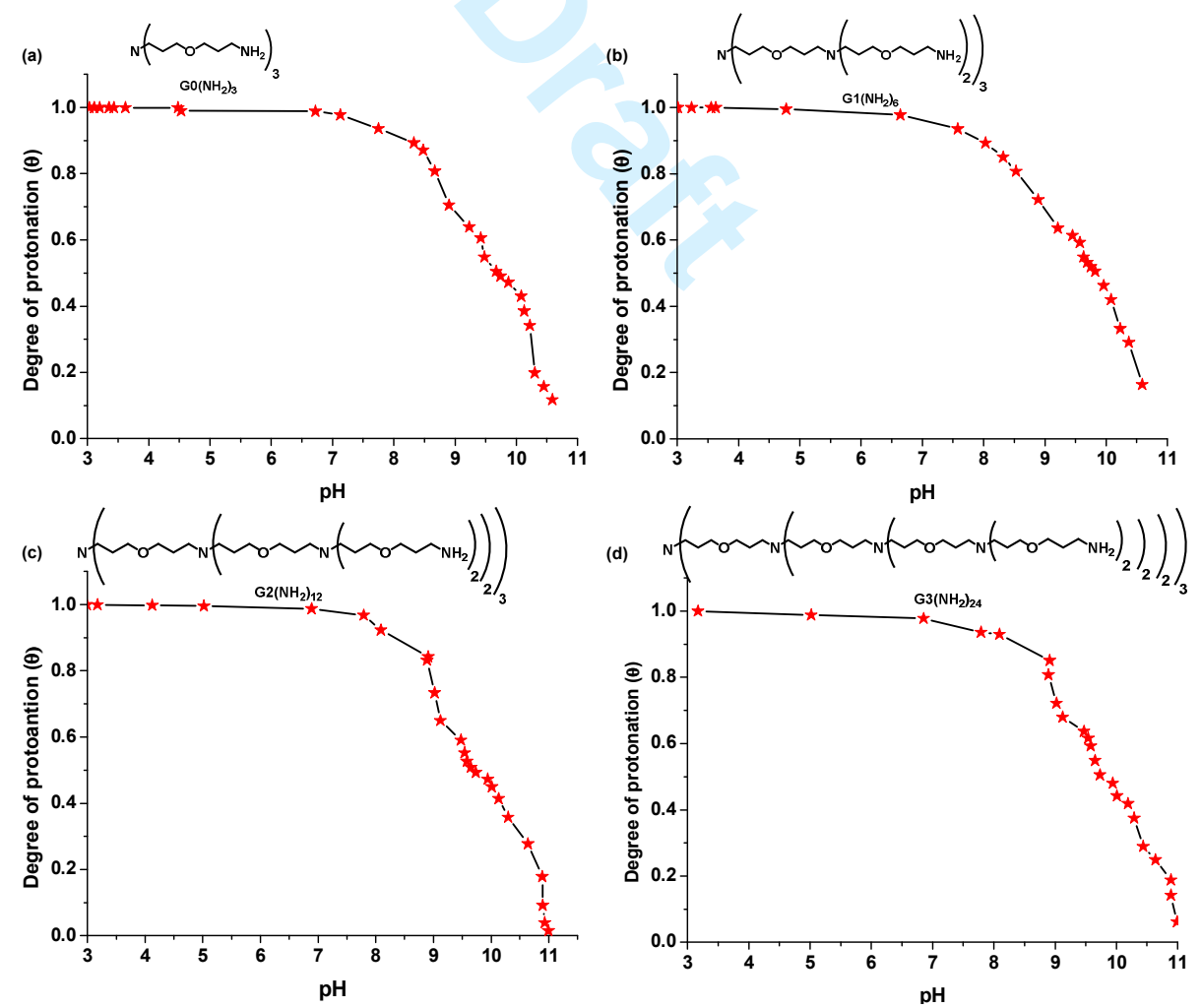

$6 \quad$ Figure 9. Plots of degree of protonation $v s \mathrm{pH}$. 


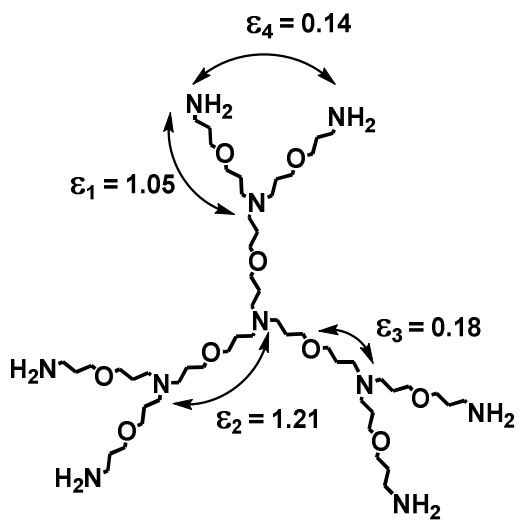

2 Figure 10. Pair-interaction parameters used to compute $\mathrm{pK}$ values.

3 Table 1. pK values of $\mathbf{G O}\left(\mathbf{N H}_{2}\right)_{3}$ and $\mathbf{G 1}\left(\mathbf{N H}_{2}\right)_{6}$, obtained experimentally and calculated using 4 the Ising model.

\begin{tabular}{ccccc}
\hline & \multicolumn{2}{c}{$\mathbf{p K} \mathbf{n}_{\mathbf{n}}$ values of $\mathbf{G 0}\left(\mathbf{N H}_{\mathbf{2}}\right)_{\mathbf{3}}$} & \multicolumn{2}{c}{$\mathbf{p K} \mathbf{n}_{\mathbf{n}}$ values of $\mathbf{G 1}\left(\mathbf{N H}_{\mathbf{2}} \mathbf{~}_{\mathbf{6}}\right.$} \\
\hline $\boldsymbol{n}^{*}$ & Experimental & Ising model & Experimental & Ising model \\
\hline $\mathbf{1}$ & 10.14 & 10.14 & 10.76 & 10.77 \\
$\mathbf{2}$ & 10.10 & 9.8 & 10.30 & 10.28 \\
$\mathbf{3}$ & 9.26 & 9.3 & 10.05 & 10.02 \\
$\mathbf{4}$ & 6.96 & 6.7 & 9.84 & 9.87 \\
$\mathbf{5}$ & - & - & 9.72 & 9.71 \\
$\mathbf{6}$ & - & - & 9.61 & 9.56 \\
$\mathbf{7}$ & - & - & 8.01 & 7.96 \\
$\mathbf{8}$ & - & - & 7.48 & 7.64 \\
$\mathbf{9}$ & - & - & 7.00 & 7.27 \\
$\mathbf{1 0}$ & - & - & 5.13 & 5.02 \\
\hline
\end{tabular}

$5 \quad{ }^{*} n=1$ to $\mathrm{N}$, where $\mathrm{N}=$ total number of amines in dendrimer 
1

a)<smiles>NCCCN(CCN)CCN</smiles>

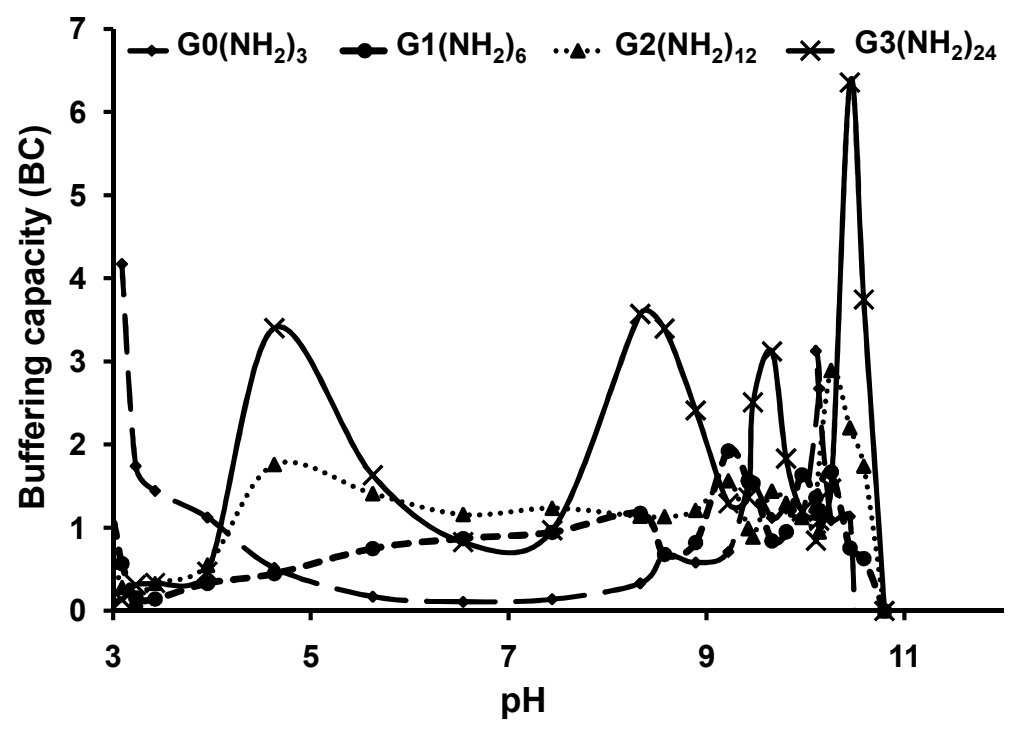

Figure 11. Buffering capacity of PETIM dendrimers of generations G0 to G3.

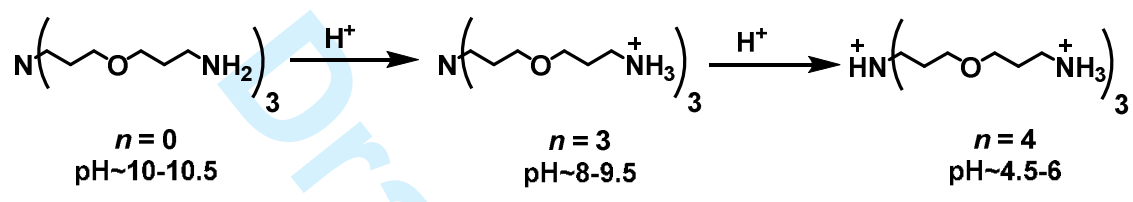<smiles>NCON(ON(N)N)ON(ON(N)N)ON(N)CN</smiles><smiles>C=C[C@H](C)CC(=O)N(C)CCOCCN(C)CCOCCN(C)C</smiles>

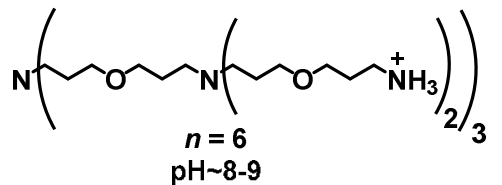

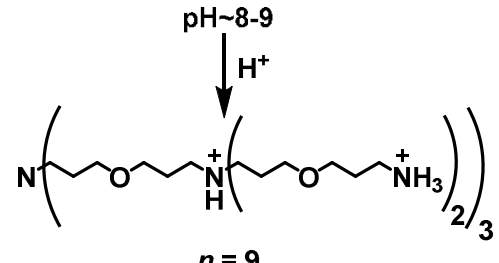
$n=10$ $\mathrm{pH} \sim 6-8$

Figure 12. Protonation mechanism in (a) $\mathbf{G 0}\left(\mathbf{N H}_{2}\right)_{3}$; (b) $\mathbf{G 1}\left(\mathbf{N H}_{2}\right)_{6}$. 
2
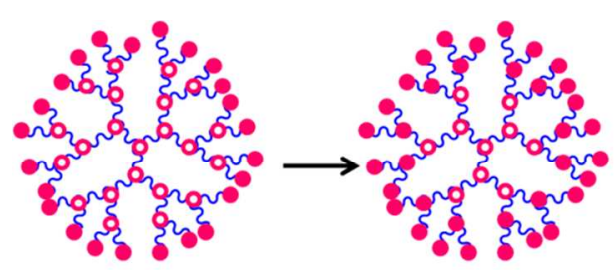

$\mathrm{pH}$ 8-9.5

$\mathrm{pH} 7-8$
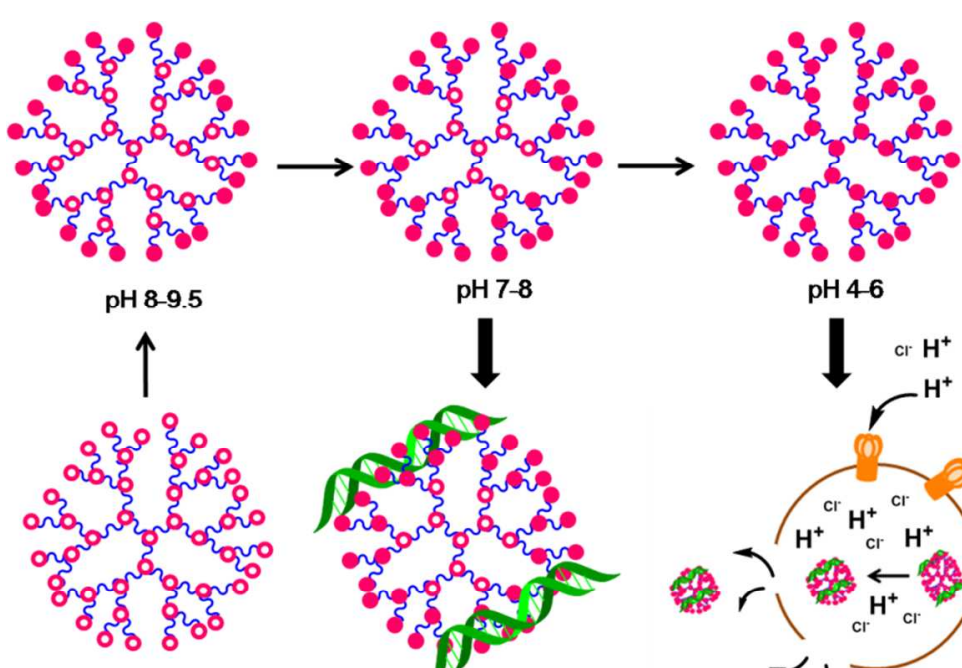

pH 10-11
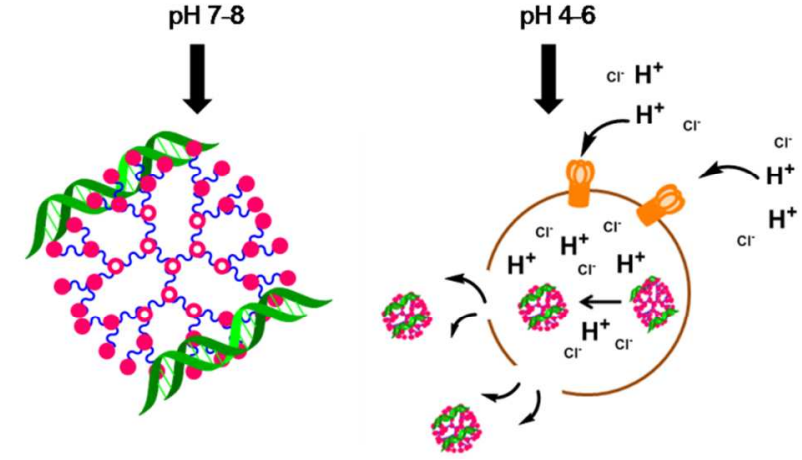